\title{
Antifungal Susceptibility Testing of Fusarium: A Practical Approach
}

\author{
Abdullah M. S. Al-Hatmi 1,2,3,*, Ilse Curfs-Breuker ${ }^{4}$, G. Sybren de Hoog 1,5,6, Jacques F. Meis ${ }^{2,4}$ \\ and Paul E. Verweij ${ }^{2,7}$ \\ 1 Westerdijk Fungal Biodiversity Institute, PO Box 85167, 3508 AD Utrecht, The Netherlands; \\ s.hoog@westerdijkinstitute.nl \\ 2 Centre of Expertise in Mycology Radboud University Medical Centre, Canisius Wilhelmina Hospital, \\ 6500HB Nijmegen, The Netherlands; jacques.meis@gmail.com (J.F.M.); Paul.Verweij@radboudumc.nl (P.E.V.) \\ 3 Ministry of Health, Directorate General of Health Services, PO Box 393, 100 Muscat, Oman \\ 4 Department of Medical Microbiology and Infectious Diseases, Canisius Wilhelmina Hospital, \\ 6500HB Nijmegen, The Netherlands; i.breuker@cwz.nl \\ 5 Basic Pathology Department, Federal University of Paraná State, Curitiba, 81540-970 Paraná, Brazil \\ 6 Biological Sciences Department, Faculty of Science, King Abdulaziz University, \\ PO Box 80203 Jeddah, Saudi Arabia \\ 7 Department of Medical Microbiology, Radboud University, Nijmegen Medical Centre, \\ 6500GS Nijmegen, The Netherlands \\ * Correspondence: abdullaalhatmi@gmail.com; Tel.: +31-30-2122600; Fax: +31-30-2512097
}

Academic Editors: Ana Alastruey-Izquierdo and Stéphane Ranque

Received: 12 March 2017; Accepted: 19 April 2017; Published: 26 April 2017

\begin{abstract}
In vitro susceptibility testing of Fusarium is becoming increasingly important because of frequency and diversity of infections and because resistance profiles are species-specific. Reference methods for antifungal susceptibility testing (AFST) are those of Clinical and Laboratory Standards Institute (CLSI) and European Committee on Antimicrobial Susceptibility (EUCAST), but breakpoints (BPs) have not yet been established. One of the problems is that phylogenetic distances between Fusarium species are much smaller than between species of, e.g., Candida. Epidemiological cutoff values (ECVs) for some Fusarium species have been determined in order to differentiate wild-type from non-wild-type isolates. In clinical routine, commercially available assays such as Etest, Sensititre or others provide essential agreement with reference methods. Our objective is to summarize antifungal susceptibility testing of Fusarium genus in the clinical laboratory: how to do it, when to do it, and how to interpret it.
\end{abstract}

Keywords: Fusarium; susceptibility test; clinical laboratory; CLSI; EUCAST; Etest

\section{Introduction}

Species of the genus Fusarium are involved in a gamut of human infections. Keratitis and onychomycosis are prevalent in immunocompetent individuals [1]. Mycotic keratitis is a worldwide important ophthalmic problem causing visual disability due to its protracted course and unfavorable response. In half of the cases in endemic areas like the South of India, the filamentous fungi Aspergillus and Fusarium are the most common species causing keratitis [2] while immunocompromised hosts with hematological malignancies and those subjected to solid organ transplant, allogeneic bone marrow transplant, or peritoneal dialysis $[3,4]$ are at risk of disseminated, frequently fatal infections. Fungemia in severely compromised patients leads to local necrosis after secondary cutaneous dissemination. In very rare cases, Fusarium can also cause skin infections characterized by small, painless papules which quickly progress to painless ulcers with black eschars [5]. 
Delayed initiation of antifungal therapy due to non-optimal diagnosis of mold infections are associated with increased mortality rates and may lead to excessive drug use in prophylaxis and therapy [1,6]. The Fusarium solani species complex contains many opportunistic species (e.g., F. falciforme, F. keratoplasticum and F. petroliphilum) with high prevalence, but other Fusarium groups are also important, such as F. oxysporum, F. verticillioides and F. proliferatum, and susceptibility to antifungal agents varies between species [7]. Treatment strategies for fusariosis have been evaluated [8] which led to the European Society of Clinical Microbiology and Infectious Diseases (ESCMID) ESCMID and European Confederation of Medical Mycology (ECMM) guidelines for management of hyalohyphomycosis caused by Fusarium and other non-melanized fungi [9]. Multiresistance to antifungals, observed in all Fusarium species, is intrinsic therefore these fungi are notoriously difficult to treat.

Fusarium species do not have a normal minimum inhibitory concentration (MIC) and minimum effective concentration (MEC) distribution $[10,11]$ and therefore prediction of antifungal susceptibility of a single strain is difficult. However, at least the species show different tendencies in their susceptibility against various antifungal compounds [11]. Susceptibility testing should be included in the routine patient management to optimize appropriate therapy, particularly in severe infections. From an epidemiological point of view, little is known about the prevalence of resistance in Fusarium infections, due to the fact that most of the laboratories do not routinely perform antifungal susceptibility testing and also because many laboratories face difficulties in correctly identifying species of Fusarium.

The role of the clinical microbiology laboratory is important to confirm susceptibility to the chosen empirical antifungal agents, or to detect resistance in individual Fusarium isolates. From a practical perspective, clinicians often perceive such test results to be at least as important as the identity of the etiologic agents. The goal of this article is to provide a review of current concepts in laboratory methods and approaches of antifungal susceptibility testing that serve to assist clinicians in making optimal antifungal decisions for treatment of fusariosis.

\section{Fusarium Species Identification in the Clinical Setting}

Accurate identification of Fusarium species from human samples down to species level is important not only from an epidemiological viewpoint, but also for choosing the appropriate antifungal treatment. However, rapid identification of Fusarium isolates from clinical samples is particularly important given their innately variable antifungal susceptibility profiles, mainly for amphotericin B, voriconazole and posaconazole $[4,11]$, but is complicated by the absence of diagnostic morphological features and also increasing number of emerging pathogenic species.

The genus Fusarium was divided into sections [12] but the current classification scheme replaces the designation "section" with "complex" [13]. Currently, the genus Fusarium is classified into 20 complexes that are comprised of related species [13]. Identification of Fusarium to the genus level is possible in the clinical microbiology laboratories relying mainly on morphology-based identification by recognizing macroscopic (colony appearance, texture/structure, pigmentation and colour of exudates) and microscopic (conidiogenous cells, (type and size of conidia) and type of conidiogeneisis). However, difficulties exist when using phenotype-based scheme because these characteristics are unstable and clinical Fusarium sometimes manifest atypically with sporulation. Furthermore, members of the same complex have overlapping morphological characteristics, with several genetically distinct species existing within the genus Fusarium.

Clinically, identification of unknown Fusarium clinical isolates to species may be important given that different species have variable susceptibilities to multiple antifungal drugs. Thus, knowledge of the species identity may influence the choice of appropriate antifungal therapy. The use of molecular genetic data appears to be essential to recognize monophyletic Fusarium species. Multilocus data have been applied to separate closely related taxa and provide support for species borderlines in Fusarium [14] as successfully used in other fungi. DNA sequencing of partial genes have been used to supplement morphological identification of Fusarium species. Use of the nuclear ribosomal internal 
transcribed spacer (ITS) sequence should be sufficient to place most isolates within the appropriate complex or Fusarium genus, but will not provide sufficient sensitivity to discriminate among individual species within the complex. Protein-coding genes are also in use, such as RNA polymerase (RPB1/2), $\beta$-tubulin (BT2), elongation factor (TEF1) [15]. TEF1 has been widely used for species identification in Fusarium. Sequences for this gene are available through GenBank and through the more focused Fusarium-ID [16], or Fusarium MLST [17]. Some single-copy protein-coding genes such as RPB1 and RPB2 are also promising for Fusarium identification [13].

Another promising approach for the quick identification of Fusarium is matrix-assisted laser desorption ionization-time-of-flight (MALDI-TOF) [18]. MALDI-TOF MS uses species-specific patterns of peptides and protein masses to identify microorganisms. These peptides are converted into ions by either addition or loss of one or multiple protons [19]. Several studies have been conducted on Fusarium species with high success rates of $82 \%-99 \%$ [20-22]. This method was performed in the F. fujikuroi species complex. A database was built as a result of this research which can be used as a future reference tool [18].

\section{Technical Reference of Antifungal Susceptibility Testing Methods for Fusarium}

Antifungal susceptibility testing is a very dynamic field of medical mycology. There are two recognized standard methods for the performance of antifungal susceptibility testing of Fusarium species that apply broth microdilution (BMD), i.e., the Clinical and Laboratory Standards Institute (CLSI) [23] and the European Committee on Antimicrobial Susceptibility Testing (EUCAST) [24]. These methods provide MIC data for all classes of antifungal agents that are both quantitatively and qualitatively comparable [25,26]. Alastruey-Izquierdo et al. [27] indicated that in vitro antifungal susceptibility testing plays an increasingly important role in guiding clinicians in giving the proper antifungals, in drug development programs, and for tracing the development of antifungal resistance in epidemiologic studies. Recently, Espinel-Ingroff et al. [28] established epidemiological cutoff values (ECVs) for some species in order to distinguish wild-type ( $\mathrm{wt}$; is the population of strains in a species/drug combination with no detectable acquired resistance mechanism) from non-wild-type (non-wt; agents with decreased susceptibility to a certain drug). Clinical interpretative breakpoints (CBPs) for in vitro antimicrobial susceptible testing for Fusarium are not yet established but epidemiological cutoff values (ECVs) for three Fusarium species have been suggested [28].

\section{In Vitro Antifungal Susceptibility Testing}

Several antifungal agents have been developed and are becoming available for clinical use [29]. Even though standardized in vitro susceptibility testing has been developed by CLSI and EUCAST yielding reproducible results, correlation with clinical outcome is still an enigma. The methods measure antifungal activity, expressed as the minimum inhibitory concentration (MIC) of an antifungal, which indicates the minimal concentration of drug able to inhibit fungal growth. Furthermore, both methods are useful to screen for resistant strains and determine the potential therapeutic value of a new antifungal agent [30]. Of note, several studies have shown that the in vitro results may be influenced by factors such as inoculum size, composition and $\mathrm{pH}$ of the medium, and incubation temperature and duration [31-33].

Establishing correlation between in vitro susceptibility tests and clinical outcome has been difficult [34]. According to the "90-60" Rule [35], infections due to susceptible isolates respond to therapy $\sim 90 \%$ of the time, whereas infections due to resistant isolates respond to therapy $\sim 60 \%$ of the time. Hence, antifungal susceptibility testing can predict the outcome of treatment only in main traits. Low MICs do not guarantee clinical success, while high MICs are associated with lower probability of a favorable response to a given antifungal agent. Applying this rule in Fusarium, the 90-60 rule reflects the fact that in vitro susceptibility of a given strain is only one of several factors influencing success of therapy. Despite the intrinsic resistance in Fusarium, in vitro testing remains useful in guiding 
clinicians in taking the right therapeutic decision because many Fusarium species show species-specific antifungal profiles $[4,11]$.

\section{Correlation between In Vitro and In Vivo}

The MIC concept remains the only important parameter for defining antifungal activity and predicting antifungal potency against the fungus at hand. Despite the advantages that MICs offer in the clinical setting, a drawback is the lack of information that they provide concerning antimicrobial activity over time. It seems that prediction of the therapeutic success based on the MIC of a fungal strain is not always possible, because studies conducted until now have shown a poor correlation between the in vitro data with the in vivo outcome. For example, high MICs of itraconazole for a Fusarium strain isolated from a mycetoma case have been found, but the patient improved and completely recovered using itraconazole [36]. Various host factors affect the response to antifungal drugs, such as underlying disease, host immune function, catheter removal, surgical interventions, and pharmacokinetic parameters [37]. Molecular mechanisms of antifungal resistance have not been studied in Fusarium, however, molecular characterization of resistance mechanism and improvements of antifungal susceptibility testing methods is important [38].

\section{EUCAST vs. CLSI}

In vitro antifungal susceptibility profiles of Fusarium species demonstrate high MICs to most antifungal agents [10,11,39-54]. Notably, some species may exhibit different patterns of susceptibility: F. solani species complex are usually resistant to azoles and exhibit higher amphotericin B MIC values than other species, whereas F. oxysporum and F. verticilloides may be susceptible to voriconazole and posaconazole [10,11,55]. The echinocandins are not active against Fusarium spp. [4,11,54].

The CLSI and EUCAST are different from each other but in terms of MIC values, they are very similar when tested for azoles (posaconazole and voriconazole), and reading is performed after 48 or $72 \mathrm{~h}$ of incubation. The two methods differ in the amount of glucose present in the media $(0.2 \%$ and $2 \%$, respectively), fungal inoculum (10 times higher in EUCAST), in the type of microtiter wells used (flat bottom versus " $U$ " shaped) and in the concentration of DMSO ( $0.5 \%$ and $1 \%$, respectively). Reading of the microliter plate is done by spectrophotometric for EUCAST and visually for CLSI. Despite some differences in inoculum size, medium composition and well shape, the two standards have proved to yield comparable results. Both methods introduce the concept of Minimum Effective Concentration (MEC) for reading echinocandin results: transition point of hyphae from normal to aberrant hyphae, evidenced by appearance of granules or clusters on the bottom of the wells of the microplates, although this is not always easy to see and may require microscopic observation. Reading of the MEC, EUCAST indicates that there are still no reliable methods for the study of the sensitivity of fungi to echinocandins [24]. Assuring quality of test performance and results (reagents, inoculum and procedure) recommended reference strains are included. EUCAST recommended, among others, the strains A. fumigatus ATCC 46645, A. flavus ATCC 204305 and ATCC 204304. CLSI recommended, among others, the use of Paecilomyces variotii ATCC MYA 3630 and A. flavus ATCC 204304.

Good correlation is obtained between MICs from CLSI and EUCAST for amphotericin B, voriconazole and posaconazole among Fusarium species [56], with categorical agreement (CA) of 100\%, $95 \%$ and $75 \%$, respectively, differing within \pm 2 dilutions [56]. In general, the MICs for amphotericin B spanned a range of 0.25 to $8 \mu \mathrm{g} / \mathrm{mL}$ with the CLSI and the EUCAST methods and in a wider range of $0.25-32$ for voriconazole and posaconazole with both methods.

\section{Etest and Other Commercial Methods}

The Etest method is based upon the establishment of a stable concentration gradient of an antimicrobial agent following diffusion from a plastic strip into an agar medium. When an Etest strip is placed upon an agar plate that has been inoculated with a test organism and incubated for 24 to $48 \mathrm{~h}$, an ellipse of growth inhibition occurs, and the intersection of the ellipse with 
the numeric scale on the strip provides an indication of the MIC. MICs determined by Etest generally agree with those determined by CLSI and EUCAST methods; however, this agreement may vary depending upon the antifungal agent tested, the choice of agar medium, and the fungal species [56,57]. Al-Hatmi et al. [56] reported that the overall agreement between the CLSI, EUCAST and Etest for drugs tested (amphotericin B, voriconazole and posaconazole) was slightly higher with EUCAST (90-100\%) than with CLSI (85-95\%). Etest thus can be considered as an appropriate method to determine the resistance in vitro to amphotericin $\mathrm{B}$, voriconazole and posaconazole. For echinocandins, insufficient comparative data are available. Other commercially available alternatives have been developed, often employing a microdilution format and spectrophotometric or colorimetric reading [58]. These methods include Sensititre YeastOne ${ }^{\circledR}$ (bioMerieux S.A., Marcy-l'Étoile, France) as well as panels for disk diffusion. Most of these tests have not been validated for antifungal susceptibility testing of Fusarium.

\section{When Should AFST Be Done for Fusarium?}

According to the different clinical experiences, susceptibility testing of Fusarium should be done to optimize the therapy of the individual patient or for epidemiological purposes. It is recommended to perform the MIC if the fungus has been isolated from sterile biological sites, in case of deep infection in patients undergoing antifungal therapy, in the event of therapeutic failure, when the isolated species is rare and/or emerging or in case of a particular species for which there is the suspicion that it may be resistant or less sensitive to the employed antifungal [9].

\section{Protocol}

Each laboratory needs to perform a risk assessment in collaboration with their Institutional Biological Safety Officer to determine the appropriate biosafety level for preparation of the inoculum and for pipetting of the inoculum into the plate. For Fusarium, biosafety level-2 laboratory (BSL-2) practice is required. Inoculum and microdilution plates are placed inside a plastic bag during the incubation at $35^{\circ} \mathrm{C}$. There are relatively few drugs to treat fusariosis. Below the antifungal testing procedure for Fusarium species against different antifungal drugs is described (Figure 1).
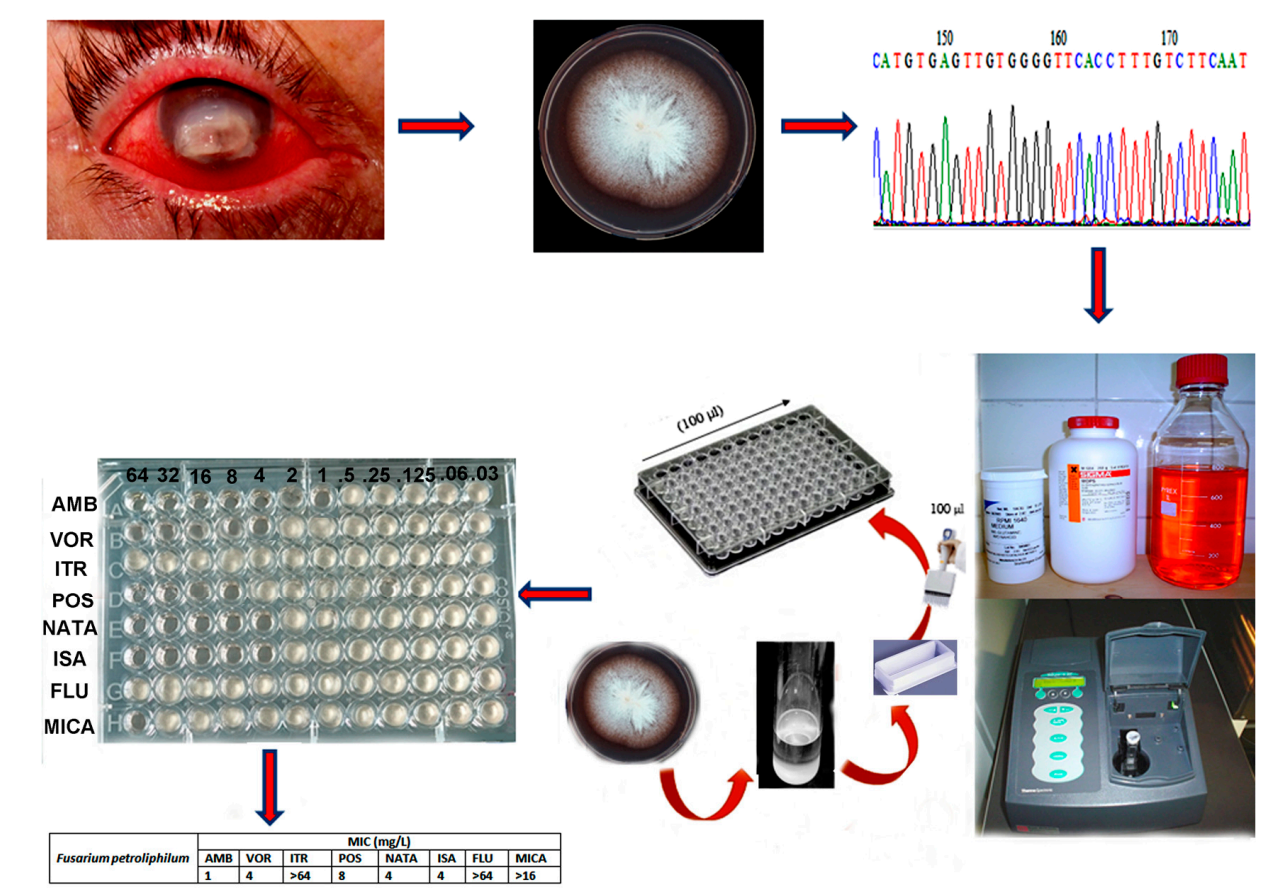

Figure 1. Antifungal susceptibility testing workflow. 


\subsection{Sample Preparation}

Prior to AFST, and according to CLSI [23], Fusarium strains should be cultured on potato dextrose agar for 48 to $72 \mathrm{~h}$ at $35^{\circ} \mathrm{C}$ and then until day seven at $25^{\circ} \mathrm{C}$ for slowly growing species. However, Al-Hatmi et al. [59] indicated that incubation of Fusarium strains for $3-5$ days at $27^{\circ} \mathrm{C}$ is suitable for AFST.

\subsection{Labeling of Materials}

Working on a laboratory bench, preparing for this procedure by start labeling culture plates, Fusarium strains, preparing the dilution tubes, saline tween 20, Dimethyl sulfoxide (DMSO), (Sigma-Aldrich-Poole, Doorset, UK), Roswell Park Memorial Institute medium (RPMI) 1640, (Sigma-Aldrich-Poole), and a microtiter AST plate with the appropriate identifiers (e.g., patient name, medical record number).

\subsection{Laboratory Personnel Preparations}

Appropriate personal protective equipment is necessary to work in the BSL-2. BSL-2 practices, containment, equipment and facilities are recommended, especially the wearing of a laboratory coat, safety glasses and disposable gloves; the gloves must be impervious to organic solvents.

\subsection{Preparation of the Biological Safety Cabinet}

Prepare the biological safety cabinet (BSC) by disinfecting the surface and placing a paper towel soaked with disinfectant approximately 6 inches from the air vent panel. Preferably, waste container should be placed on the left, and a small vortex on the right. Inoculating loops, cotton swabs, pipets and tips are placed beside the paper towel. A rack with the test fungi (on solid medium) should be placed on the paper towel.

\subsection{Preparation of the Inoculum}

Working in the BSL-2 cabinet, the cotton swabs are moistened with sterile saline with $0.005 \%$ Tween 20 and spores are harvested from the colonies on solid medium. Suspensions are made in saline with $0.005 \%$ Tween 20 (approximate 0.5 Mc Farland; equivalent to $1-5 \times 10^{6} \mathrm{CFU} / \mathrm{mL}$ ) standard. After allowing heavy particles to settle for three to five minutes, the upper homogeneous suspension is transferred to a sterile tube and vortexed for $15 \mathrm{~s}$. The transmission is measured with a spectrophotometer at $530 \mathrm{~nm}$ that ranges from $0.15-0.17(65 \%-70 \% \mathrm{~T})$. The 1:50 (CLSI) inoculum dilution will be $2 \times$ (twofold) more concentrated than the density needed and 10 $\times$ (EUCAST) approximately $0.4-5 \times 10^{4}\left(\right.$ CLSI) and $2-5 \times 10^{6}($ EUCAST) .

\subsection{Calibration of Spectrophotometer and Measuring Transmission}

The transmission (T) option should be selected (" $530 \mathrm{~nm}-100 \% \mathrm{~T}^{\prime}$ ) setting it as a blank using saline Tween 20. Once the blank is set then the cuvette with the sample suspension is placed in the cuvette holder with its smooth side to the front, and the lid is closed. The transmission of this particular suspension is measured " $530 \mathrm{~nm}$ and measured \% $\mathrm{T}$ ", it should be between $65-70$ for Fusarium species.

\subsection{Inoculation}

The procedure involves preparing two-fold dilutions of the antifungal drugs. This can be achieved by dilution of antifungal in serial dilutions (e.g., 4, 8, 16, 32 and $64 \mu \mathrm{g} / \mathrm{mL}$ ) in a liquid growth medium (RPMI 1640) dispensed in tubes containing a minimum volume of $2 \mathrm{~mL}$ (macrodilution) or with smaller volumes using 96-well micro-titration plates. Then, each well is inoculated with antifungals prepared in the same medium after dilution of standardized microbial suspension adjusted to $0.5 \mathrm{McFarland}$ scale. Also the growth control wells are inoculated with $100 \mu \mathrm{L}$ of sterile drug-free medium, and $100 \mu \mathrm{L}$ of the same inoculum suspension. Following $48 \mathrm{~h}$ incubation at $35^{\circ} \mathrm{C}$, the microdilution plates are 
examined for visible Fusarium growth. The lowest concentration of antifungal that prevented growth represented the minimal inhibitory concentration (MIC).

\subsection{Interpretation of Results}

Microdilution plates can be read manually using a mirror as an aid or with an automated plate reader such as the Vizion (TREK Diagnostic Systems, Cleveland, OH, USA). The plates can be examined as soon as 24 to $48 \mathrm{~h}$ after inoculation. The growth control wells are also examined to determine if they are positive (i.e., have a deposit of cells at the bottom of the well). If the growth control wells are not positive, the plate should re-incubated and re-examined (e.g., 24,48 and $72 \mathrm{~h}$ ) or until the growth control wells are positive.

The MIC of amphotericin B, voriconazole and the newer azoles is the well with the lowest concentration with $100 \%$ inhibition of growth (compared to the growth control well). In the case of echinocandins against Fusarium the minimal effective concentration (MEC) is determined. The MEC is defined as the lowest concentration of drug that leads to the abnormal growth of the fungus (small, rounded, and/or compact hyphal forms) in comparison to the control hyphal growth. ECVs determined by Espinel-Ingroff et al. [28] using CLSI methodology for F. oxysporum and F. solani species complexes and for F. verticillioides of the fujikuroi SC are as follows: for amphotericin B $4 \mu \mathrm{g} / \mathrm{mL}$ (F. verticillioides) and $8 \mu \mathrm{g} / \mathrm{mL}$ (F. oxysporum SC and F. solani SC); for posaconazole, $2 \mu \mathrm{g} / \mathrm{mL}$ (F. verticillioides), $8 \mu \mathrm{g} / \mathrm{mL}$ (F. oxysporum SC), and $32 \mu \mathrm{g} / \mathrm{mL}$ (F. solani SC); for voriconazole, $4 \mu \mathrm{g} / \mathrm{mL}$ (F. verticillioides), $16 \mu \mathrm{g} / \mathrm{mL}$ (F. oxysporum SC), and $32 \mu \mathrm{g} / \mathrm{mL}$ (F. solani SC); and for itraconazole, $32 \mu \mathrm{g} / \mathrm{mL}$ (F. oxysporum SC and F. solani SC).

In general, there is a great variability in regard to their in vitro susceptibility to different antifungal agents. In 2003, a study from USA and Canada using a percentage of strains $<1 \mu \mathrm{g} / \mathrm{mL}$ to indicate susceptibility showed $82 \%$ were susceptible to amphotericin B and $18 \%$ to voriconazole and posaconazole and no strains were considered susceptible to itraconazole and caspofungin [60]. In 2005, 57 strains of Fusarium from Mexico had $\mathrm{MIC}_{90 \%}>1 \mu \mathrm{g} / \mathrm{mL}$ for itraconazole, posaconazole and voriconazole [61]. In a study in Spain with 44 isolates of Fusarium spp. showed that F. oxysporum, F. solani and F. verticillioides were resistant to itraconazole, voriconazole and posaconazole with $\mathrm{MIC}_{90 \%} \geq 8 \mu \mathrm{g} / \mathrm{mL}$. Both $F$. solani and F. verticillioides had high $\mathrm{MIC}_{90 \%}$ to amphotericin $\geq 4 \mu \mathrm{g} / \mathrm{mL}$ whereas the $\mathrm{MIC}_{90 \%}$ for F. oxysporum was $1 \mu \mathrm{g} / \mathrm{mL}$ indicating susceptibility to amphotericin B [62]. One year later, another Spanish study, reported very high MICs for F. oxysporum, F. proliferatum, F. solani and F. verticillioides [10]. A study in the Netherlands in 2015 focused on fujikuroi complex and used molecular methods to identify species and then compare the identification to their antifungal patterns [11]. The species were as follows: 10 strains of $F$. verticillioides, 9 each of $F$. proliferatum and F. sacchari, 7 each of F. acutatum, F. fujikuroi, F. napiforme and F. nygamai, 6 each of F. ananatum and F. thapsinum, 5 of F. anthophilum, 4 of F. andiyazi, 3 of F. subglutinans and 1 of F. temperatum. Amphoterecin $\mathrm{B}$ was the most active drug with MICs ranging between 0.125 and $8 \mu \mathrm{g} / \mathrm{mL}$. For fluconazole, itraconazole, and micafungin all strains showed high MIC/MEC values of $\geq 64,>16$ and $8 \mu \mathrm{g} / \mathrm{mL}$, respectively. The Fusarium strains tested in this study had variable susceptibilities to Amphoterecin B, voriconazole, posaconazole and isavuconazole, with MICs ranging between 0.125 and $8 \mu \mathrm{g} / \mathrm{mL}$ for amphotericin B, 0.5 to $8 \mu \mathrm{g} / \mathrm{mL}$ for voriconazole (one strain tested had a MIC of $16 \mu \mathrm{g} / \mathrm{mL}$ ); 0.25 to $\geq 16 \mu \mathrm{g} / \mathrm{mL}$ for posaconazole and 1 to $\geq 16 \mu \mathrm{g} / \mathrm{mL}$ for isavuconazole [11]. The authors concluded that amphotericin B seemed to be the most active agent followed by voriconazole; however, they suggested that proper identification of species within the complex should be done in order to provide correct information for treatment especially F. thapsinum and F. nygamai because both species showed high MICs to the most drugs tested. Another study from India looked at 60 Fusarium isolates mainly from F. solani complex from keratitis cases and based on the observed MIC data in this study, authors reported that amphoterecin B and voriconazole had $\leq 4 \mu \mathrm{g} / \mathrm{mL}$ and natamycin $\leq 4 \mu \mathrm{g} / \mathrm{mL}$ are potential antifungal agents for the treatment of human keratomycosis caused by Fusarium [11]. Overall, Fusarium showed high MICs against fluconazole, itraconazole and echinocandins. 
Since most strains have high MICs (intrinsic resistance) and since there is no breakpoints for susceptibility in the CLSI and EUCAST, we cannot determine susceptible/resistant, but different degrees of resistance at most can be determined in different strains. As the susceptibility profile is isolate dependent, antifungal susceptibility testing should be performed especially for any Fusarium involved in an invasive infection. Although susceptibility testing for Fusarium has lagged behind that for others like Aspergillus and Candida, much progress has been made over the past decade. Such knowledge should improve the clinician's ability to select the best choice among the antifungal agents available. Further work needs to be done to correlate in vitro findings with in vivo, either using animal models or clinical outcomes. The collection of such data will allow for the establishment of interpretive breakpoints, which have already been established for Aspergillus and Candida species with some antifungal agents.

\section{Conclusions}

Prior to antifungal susceptibility testing, proper identification of the Fusarium strain is absolutely compulsory. Susceptibility testing should be performed in particular infection categories: invasive forms, infection in immunosuppressed individuals, upon therapeutic breakthrough infections, cases of keratitis or if antifungal treatment clinically failed. Susceptibility testing should be performed only if each analytical run includes the appropriate quality controls in accordance with the reference standards.

Conflicts of Interest: The authors declare no conflict of interest.

\section{References}

1. Al-Hatmi, A.M.; Bonifaz, A.; Ranque, S.; de Hoog, G.S.; Verweij, P.E.; Meis, J.F. Current antifungal treatment of fusariosis. Int. J. Antimicrob. Agents 2017, in press.

2. Ansari, Z.; Miller, D.; Galor, A. Current thoughts in fungal keratitis: Diagnosis and treatment. Curr. Fungal Infect. Rep. 2013, 7, 209-218. [CrossRef] [PubMed]

3. Muhammed, M.; Coleman, J.J.; Carneiro, H.A.; Mylonakis, E. The challenge of managing fusariosis. Virulence 2011, 2, 91-96. [CrossRef] [PubMed]

4. Al-Hatmi, A.M.S.; Meis, J.F.; de Hoog, G.S. Fusarium: Molecular diversity and intrinsic drug resistance. PLoS Pathog. 2016, 12, e1005464. [CrossRef] [PubMed]

5. Jiang, Y.; Al-Hatmi, A.M.; Xiang, Y.; Cao, Y.; van den Ende, A.H.; Curfs-Breuker, I.; Meis, J.F.; Lu, H.; de Hoog, G.S. The concept of ecthyma gangrenosum illustrated by a Fusarium oxysporum infection in an immunocompetent individual. Mycopathologia 2016, 181, 759-763. [CrossRef] [PubMed]

6. Badiee, P.; Hashemizadeh, Z. Opportunistic invasive fungal infections: Diagnosis \& clinical management. Indian J. Med. Res. 2014, 139, 195-204. [PubMed]

7. Al-Hatmi, A.M.; Hagen, F.; Menken, S.B.J.; Meis, J.F.; de Hoog, G.S. Global molecular epidemiology and genetic diversity of Fusarium, a significant emerging human opportunist from 1958-2015. Emerg. Microbes Infect. 2016, 5, e33. [CrossRef] [PubMed]

8. Nucci, M.; Marr, K.A.; Vehreschild, M.J.; de Souza, C.A.; Velasco, E.; Cappellano, P.; Carlesse, F.; Queiroz-Telles, F.; Sheppard, D.C.; Kindo, A.; et al. Improvement in the outcome of invasive fusariosis in the last decade. Clin. Microbiol. Infect. 2014, 20, 580-585. [CrossRef] [PubMed]

9. Tortorano, A.M.; Richardson, M.; Roilides, E.; van Diepeningen, A.; Caira, M.; Munoz, P.; Johnson, E.; Meletiadis, J.; Pana, Z.D.; Lackner, M.; et al. ESCMID and ECMM joint guidelines on diagnosis and management of hyalohyphomycosis: Fusarium spp., Scedosporium spp. and others. Clin. Microbiol. Infect. 2014, 20, 27-46. [CrossRef] [PubMed]

10. Alastruey-Izquierdo, A.; Cuenca-Estrella, M.; Monzon, A.; Mellado, E.; Rodriguez-Tudela, J.L. Antifungal susceptibility profile of clinical Fusarium spp. isolates identified by molecular methods. J. Antimicrob. Chemother. 2008, 61, 805-809. [CrossRef] [PubMed]

11. Al-Hatmi, A.M.S.; van Diepeningen, A.D.; Curfs-Breuker, I.; de Hoog, G.S.; Meis, J.F. Specific antifungal susceptibility profiles of opportunists in the Fusarium fujikuroi complex. J. Antimicrob. Chemother. 2015, 70, 1068-1071. [CrossRef] [PubMed] 
12. Nelson, P.E.; Dignani, C.M.; Anaissie, E.J. Taxonomy, biology, and clinical aspects of Fusarium species. Clin. Microbiol. Rev. 1994, 7, 479. [CrossRef] [PubMed]

13. O'Donnell, K.; Rooney, A.P.; Proctor, R.H.; Brown, D.W.; McCormick, S.P.; Ward, T.J.; Frandsen, R.J.; Lysøe, E.; Rehner, S.A.; Aoki, T.; et al. RPB1 and RPB2 phylogeny supports an early cretaceous origin and a strongly supported clade comprising all agriculturally and medically important fusaria. Fungal Genet. Biol. 2013, 52, 20-31. [CrossRef] [PubMed]

14. Schroers, H.J.; Samuels, G.J.; Zhang, N.; Short, D.P.G.; Juba, J.; Geiser, D.M. Epitypification of Fusisporium (Fusarium) solani and its assignment to a common phylogenetic species in the Fusarium solani species complex. Mycologia 2016, 108, 806-819. [CrossRef] [PubMed]

15. O’Donnell, K.; Ward, T.J.; Robert, V.A.R.G.; Crous, P.W.; Geiser, D.M.; Seogchan, K. DNA sequence-based identification of Fusarium: Current status and future directions. Phytoparasitica 2015, 43, 583-595. [CrossRef]

16. Geiser, D.M.; Jimenez-Gasco, M.D.; Kang, S.C.; Makalowska, I.; Veeraraghavan, N.; Todd, J.W.; Zhang, N.; Kuldau, A.G.; O'donnell, K. FUSARIUM-ID v. 1.0: A DNA sequence database for identifying Fusarium. Eur. J. Plant. Pathol. 2004, 110, 473-479. [CrossRef]

17. O’Donnell, K.; Humber, R.A.; Geiser, D.M.; Kang, S.; Park, B.; Robert, V.A. Phylogenetic diversity of insecticolous fusaria inferred from multilocus DNA sequence data and their molecular identification via FUSARIUM-ID and Fusarium MLST. Mycologia 2012, 104, 427-445. [CrossRef] [PubMed]

18. Al-Hatmi, A.M.; Normand, A.C.; van Diepeningen, A.D.; Hendrickx, M.; de Hoog, G.S.; Renaud, P. Rapid species-level identification of opportunists in the Fusarium fujikuroi species complex using MALDI-TOF mass spectrometry. Future Microbiol. 2015, 10, 1939-1952. [CrossRef] [PubMed]

19. Singhal, N.; Kumar, M.; Kanaujia, P.K.; Virdi, J.S. MALDI-TOF mass spectrometry: An emerging technology for microbial identification and diagnosis. Front. Microbiol. 2015, 6, 791. [CrossRef] [PubMed]

20. Marinach-Patrice, C.; Lethuillier, A.; Marly, A.; Brossas, J.Y.; Gené, J.; Symoens, F.; Datry, A.; Guarro, J.; Mazier, D.; Hennequin, C. Use of mass spectrometry to identify clinical Fusarium isolates. Clin. Microbiol. Infect. 2009, 15, 634-642. [CrossRef] [PubMed]

21. De Carolis, E.; Posteraro, B.; Lass-Flörl, C.; Vella, A.; Florio, A.R.; Torelli, R.; Girmenia, C.; Colozza, C.; Tortorano, A.M.; Sanguinetti, M.; et al. Species identification of Aspergillus, Fusarium and Mucorales with direct surface analysis by matrix-assisted laser desorption ionization time-of-flight mass spectrometry. Clin. Microbiol. Infect. 2012, 18, 475-484. [CrossRef] [PubMed]

22. Triest, D.; Stubbe, D.; de Cremer, K.; Piérard, D.; Normand, A.C.; Piarroux, R.; Detandt, M.; Hendrickx, M. Use of matrix-assisted laser desorption ionization-time of flight mass spectrometry for identification of molds of the Fusarium genus. J. Clin. Microbiol. 2015, 53, 465-476. [CrossRef] [PubMed]

23. Clinical and Laboratory Standards Institute. M38-A2: Reference Method for Broth Dilution Antifungal Susceptibility Testing of Filamentous Fungi, Approved Standard-2nd ed.; CLSI: Wayne, PA, USA, 2008.

24. Arendrup, M.C.; Guinea, J.; Cuenca-Estrella, M.; Meletiadis, J.; Mouton, J.W.; Lagrou, K.; Howard, S.J.; Subcommittee on Antifungal Susceptibility Testing (AFST) of the ESCMID European Committee for Antimicrobial Susceptibility Testing (EUCAST). In EUCAST Method for the Determination of Broth Dilution Minimum Inhibitory Concentrations of Antifungal Agents for Conidia Forming Moulds Version 9.3; EUCAST: Växjö, Sweden, 2015.

25. Pfaller, M.A.; Espinel-Ingroff, A.; Boyken, L.; Hollis, R.J.; Kroeger, J.; Messer, S.A.; Tendolkar, S.; Diekema, D.J. Comparison of the Broth Microdilution (BMD) method of the European Committee on Antimicrobial Susceptibility Testing with the 24-Hour CLSI BMD Method for Testing Susceptibility of Candida Species to Fluconazole, Posaconazole, and Voriconazole by Use of Epidemiological Cutoff Values. J. Clin. Microbiol. 2011, 49, 845-850. [PubMed]

26. Pfaller, M.A.; Diekema, D.J. Progress in antifungal susceptibility testing of Candida spp. by use of clinical and laboratory standards institute broth microdilution methods, 2010 to 2012. J. Clin. Microbiol. 2012, 50, 2846-2856. [CrossRef] [PubMed]

27. Alastruey-Izquierdo, A.; Melhem, M.S.; Bonfietti, L.X.; Rodriguez-Tudela, J.L. Susceptibility test for fungi: Clinical and laboratorial correlations in medical mycology. Rev. Inst. Med. Trop. Sao Paulo 2015, 57, 57-64. [CrossRef] [PubMed] 
28. Espinel-Ingroff, A.; Colombo, A.L.; Cordoba, S.; Dufresne, P.J.; Fuller, J.; Ghannoum, M.; Gonzalez, G.M.; Guarro, J.; Kidd, E.; Meis, J.F.; Melhem, T.M.S.C.; et al. An international evaluation of MIC distributions and ECV definition for Fusarium species identified by molecular methods for the CLSI broth microdilution method. Antimicrob. Agents Chemother. 2016, 60, 1079-1084. [CrossRef] [PubMed]

29. Pianalto, K.M.; Alspaugh, A.J. New Horizons in antifungal therapy. J. Fungi 2016, 2, 26. [CrossRef]

30. Pfaller, M.A.; Barry, A.L. Evaluation of a novel colorimetric broth microdilution method for antifungal susceptibility testing of yeast isolates. J. Clin. Microbiol. 1994, 32, 1992-1996. [PubMed]

31. Doern, G.; Tubert, T.; Chapin, K.; Rinaldi, M. Effect of medium composition on results of macrobroth dilution antifungal susceptibility testing of yeasts. J. Clin. Microbiol. 1986, 24, 507-511. [PubMed]

32. Espinel-Ingroff, A.; Shadomy, S. In vitro and in vivo evaluation of antifungal agents. Eur. J. Clin. Microbiol. Infect. Dis. 1989, 8, 352-361. [CrossRef] [PubMed]

33. Rex, J.; Pfaller, M.; Walsh, T.; Chaturvedi, V.; Espinel-Ingroff, A.; Ghannoum, M.; Gosey, L.L.; Odds, F.C.; Rinaldi, M.G.; Sheehan, D.J.; et al. Antifungal susceptibility testing: Practical aspects and current challenges. Clin. Microbiol. Rev. 2001, 14, 643-658. [CrossRef] [PubMed]

34. Arendrup, M.; Perkhofer, S.; Howard, S.; Garcia-Effron, G.; Vishukumar, A.; Perlin, D.; Lass-Flörl, C. Establishing in vitro-in vivo correlations for Aspergillus fumigatus: The challenge of azoles versus echinocandins. Antimicrob. Agents Chemother. 2008, 52, 3504-3511. [CrossRef] [PubMed]

35. Arikan, S. Current status of antifungal susceptibility testing methods. Med. Mycol. 2007, 45, 569-587. [CrossRef] [PubMed]

36. Al-Hatmi, A.M.; Bonifaz, A.; Tirado-Sánchez, A.; Meis, J.F.; de Hoog, G.S.; Ahmed, S.A. Fusarium species causing eumycetoma: Report of two cases and comprehensive review of the literature. Mycoses 2017, 60, 204-212. [CrossRef] [PubMed]

37. Rex, J.H.; Pfaller, M.A. Has antifungal susceptibility testing come of age? Clin. Infect. Dis. 2002, 35, 982-989. [CrossRef] [PubMed]

38. Pfaller, M.A.; Castanheira, M.; Lockhart, S.R.; Ahlquist, A.M.; Messer, S.A.; Jones, R.N. Frequency of decreased susceptibility and resistance to echinocandins among fluconazole-resistant bloodstream isolates of Candida glabrata. J. Clin. Microbiol. 2012, 50, 1199-2103. [CrossRef] [PubMed]

39. Pujol, I.; Guarro, J.; Gené, J.; Sala, J. In Vitro antifungal susceptibility of clinical and environmental Fusarium spp. strains. J. Antimicrob. Chemother. 1997, 39, 163-167. [CrossRef] [PubMed]

40. Lewis, R.E.; Wiederhold, N.P.; Klepser, M.E. In vitro pharmacodynamics of amphotericin B, itraconazole, and voriconazole agains Aspergillus, Fusarium, and Scedosporium spp. Antimicrob. Agents Chemother. 2005, 49, 945-951. [CrossRef] [PubMed]

41. Sabatelli, F.; Pate, R.l.; Mann, P.A.; Mendrick, C.A.; Norris, C.C.; Hare, R.; Loebenberg, D.; Black, T.A.; McNicholas, P.M. In vitro activities of posaconazole, fluconazole, itraconazole, voriconazole, and amphotericin B against a large collection of clinically important molds and yeasts. Antimicrob. Agents Chemother. 2006, 50, 2009-2015. [CrossRef] [PubMed]

42. Azor, M.; Gené, J.; Cano, J.; Guarro, J. Universal in vitro antifungal resistance of genetic clades of the Fusarium solani species complex. Antimicrob. Agents Chemother. 2007, 51, 1500-1503. [CrossRef] [PubMed]

43. Guinea, J.; Peláez, T.; Recio, S.; Torres-Narbona, M.; Bouza, E. In vitro antifungal activities of isavuconazole (BAL4815), voriconazole, and fluconazole against 1007 isolates of zygomycete, Candida, Aspergillus, Fusarium, and Scedosporium species. Antimicrob. Agents Chemother. 2008, 52, 1396-1400. [CrossRef] [PubMed]

44. Lalitha, P.; Prajna, N.V.; Oldenburg, C.E.; Srinivasan, M.; Krishnan, T.; Mascarenhas, J.; Vaitilingam, C.M.; McLeod, S.D.; Zegans, M.E.; Porco, T.C.; et al. Organism, minimum inhibitory concentration, and outcome in a fungal corneal ulcer clinical trial. Cornea 2012, 31, 662-667. [CrossRef] [PubMed]

45. Lalitha, P.; Sun, C.Q.; Prajna, N.V.; Karpagam, R.; Geetha, M.; O’Brien, K.S.; Cevallos, V.; McLeod, S.D.; Acharya, N.R.; Lietman, T.M.; et al. In vitro susceptibility of filamentous fungal isolates from corneal ulcer clinical trail. Int. J. Opthalmol. 2014, 157, 318-326.

46. Lalitha, P.; Shapiro, B.L.; Srinivasan, M.; Prajna, N.V.; Acharya, N.R.; Fothergill, A.W.; Ruiz, J.; Chidambaram, J.D.; Maxey, K.J.; Hong, K.C.; et al. Antimicrobial susceptibility of Fusarium, Aspergillus and other filamentous fungi isolated from keratitis. Arch. Opthalmol. 2007, 125, 789-793. [CrossRef] [PubMed]

47. Azor, M.; Gené, J.; Cano, J.; Manikandan, P.; Venkatapathy, N.; Guarro, J. Less-frequent Fusarium species of clinical interest: Correlation between morphological and molecular identification and antifungal susceptibility. J. Clin. Microbiol. 2009, 47, 1463-1468. [CrossRef] [PubMed] 
48. Azor, M.; Gené, J.; Cano, J.; Sutton, D.A.; Fothergill, A.W.; Rinaldi, M.G.; Guarro, J. In vitro antifungal susceptibility and molecular characterization of clinical isolates of Fusarium verticillioides (F. moniliforme) and Fusarium thapsinum. Antimicrob. Agents Chemother. 2008, 52, 2228-2231. [CrossRef] [PubMed]

49. Nucci, M.; Anaissie, E. Fusarium infections in immunocompromised patients. Clin. Microbiol. Rev. 2007, 20, 695-704. [CrossRef] [PubMed]

50. O'Donnell, K.; Sutton, D.A.; Fothergill, A.; McCarthy, D.; Rinaldi, M.G.; Brandt, M.E.; Zhang, N.; Geiser, DM. Molecular phylogenetic diversity, multilocus haplotype nomenclature, and in vitro antifungal resistance within the Fusarium solani species complex. J. Clin. Microbiol. 2008, 46, 2477-2490. [CrossRef] [PubMed]

51. Tortorano, A.M.; Prigitano, A.; Dho, G.; Esposto, M.C.; Gianni, C.; Grancini, A.; Ossi, C.; Viviani, M.A. Species distribution and in vitro antifungal susceptibility patterns of 75 clinical isolates of Fusarium spp. from Northern Italy. Antimicrob. Agents Chemother. 2008, 52, 2683-2685. [CrossRef] [PubMed]

52. Taj-Aldeen, S.J.; Salah, H.; Al-Hatmi, A.M.; Hamed, M.; Theelen, B.; van Diepeningen, A.D.; Boekhout, T.; Lass-Flörl, C. In vitro resistance of clinical Fusarium species to amphotericin B and voriconazole using the EUCAST antifungal susceptibility method. Diagn. Microbiol. Infect. Dis. 2016, 85, 438-443. [CrossRef] [PubMed]

53. Hassan, A.S.; Al-Hatmi, A.M.S.; Shobana, C.S.; van Diepeningen, A.; Kredics, L.; Vágvölgyi, C.; Homa, M.; Meis, J.F.; de Hoog, G.S.; Narendran, V.; et al. Antifungal susceptibility and phylogeny of opportunistic members of Fusarium species causing human keratomycosis in India. Med. Mycol. 2016, 54, $287-294$. [CrossRef] [PubMed]

54. Daylan Cilo, B.; Al-Hatmi, A.M.; Seyedmousavi, S.; Rijs, A.J.; Verweij, P.E.; Ener, B.; de Hoog, G.S.; van Diepeningen, A.D. Emergence of fusarioses in a university hospital in Turkey during a 20-year period. Eur. J. Clin. Microbiol. Infect. Dis. 2015, 34, 1683-1691. [CrossRef] [PubMed]

55. Pfaller, M.A.; Diekema, D.J. Epidemiology of invasive mycoses in North America. Crit. Rev. Microbiol. 2010, 36, 1-53. [CrossRef] [PubMed]

56. Al-Hatmi, A.M.; Normand, A.C.; Ranque, S.; Piarroux, R.; de Hoog, G.S.; Meletiadis, J.; Meis, J.F. Comparative evaluation of Etest, EUCAST, and CLSI methods for amphotericin B, voriconazole, and posaconazole against clinically relevant Fusarium species. Antimicrob. Agents Chemother. 2017, 61. [CrossRef] [PubMed]

57. Espinel-Ingroff, A.; Pfaller, M.; Erwin, M.E.; Jones, R.N. Interlaboratory evaluation of Etest method for testing antifungal susceptibilities of pathogenic yeasts to five antifungal agents by using Casitone agar and solidified RPMI 1640 medium with 2\% glucose. J. Clin. Microbiol. 1996, 34, 848-852. [PubMed]

58. Pfaller, M.A.; Diekema, D.J.; Rinaldi, M.G. Antifungal drugs: Mechanisms of action, drug resistance, susceptibility testing and assays of activity in biological fluids. In Antibiotics in Laboratory Medicine, 5th ed.; Lorian, V., Ed.; Lippincott Williams \& Wilkins: Philadelphia, PA, USA, 2005; pp. 226-265.

59. Al-Hatmi, A.M.; Meletiadis, J.; Curfs-Breuker, I.; Bonifaz, A.; Meis, J.F.; de Hoog, G.S. In vitro combinations of natamycin with voriconazole, itraconazole and micafungin against clinical Fusarium strains causing keratitis. J. Antimicrob. Chemother. 2016, 71, 953-955. [CrossRef] [PubMed]

60. Diekema, D.J.; Messer, S.A.; Hollis, R.J.; Jones, R.N.; Pfaller, M.A. Activities of caspofungin, itraconazole, posaconazole, ravuconazole, voriconazole, and amphotericin B against 448 recent clinical isolates of filamentous fungi. J. Clin. Microbiol. 2003, 41, 3623-3626. [CrossRef] [PubMed]

61. González, G.M.; Fothergill, A.W.; Sutton, D.A.; Rinaldi, M.G.; Loebenberg, D. In vitro activities of new and established triazoles against opportunistic filamentous and dimorphic fungi. Med. Mycol. 2005, 43, 281-284. [CrossRef] [PubMed]

62. Cuenca-Estrella, M.; Gomez-Lopez, A.; Mellado, E.; Buitrago, M.J.; Monzon, A.; Rodriguez-Tudela, J.L. Head-to-head comparison of the activities of currently available antifungal agents against 3378 Spanish clinical isolates of yeasts and filamentous fungi. Antimicrob. Agents Chemother. 2006, 50, 917-921. [CrossRef] [PubMed]

(C) 2017 by the authors. Licensee MDPI, Basel, Switzerland. This article is an open access article distributed under the terms and conditions of the Creative Commons Attribution (CC BY) license (http:/ / creativecommons.org/licenses/by/4.0/). 